Bioscientia Medicina: Journal of Biomedicine \&

Translational Research

Journal Homepage: www.bioscmed.com

\title{
Effect of Leafflower (Phyllanthus niruri Linn.) treatment on kidney and uterus in sodium chloride -induced fibrotic rats
}

\section{Khairil Pahmi ${ }^{\star}$, M. Sidratullah²}

${ }^{1}$ Department of Pharmacy, Diploma of Pharmacy, Faculty of Health Science, Universitas Nahdlatul Wathan Mataram, West Nusa Tenggara, Indonesia

A R T I C L E I N F O

Keywords:

Phyllanthus Niruri Extract Fibrosis

Matrix Extracelluer

Corresponding author:

Khairil Pahmi

E-mail address:

khairilpahmibiomedis@gmail.com

All authors have reviewed and approved the final version of the manuscript.

\section{https://doi.org/10.32539/bsm.v5i3.187}

\section{A B S T R A C T}

Background: Phyllanthus niruri (local name: meniran) extract is utilized in treating kidney and uterus disease. Effects of ethanol extract of P. niruri on kidney and uterus of $2 \% \mathrm{NaCl}$ triggered fibrotic rats had been studied. Aim of Study Aim of this study to explore the effect of leafflower (Phyllanthus niruri Linn.) treatment on kidney and uterus in $2 \% \mathrm{NaCl}-$ induced fibrotic rats. Methods: Wistar rats were challenged with $2 \% \mathrm{NaCl}$ in drinking water to induce fibrotic kidney and uterus. Phyllanthus niruri extract $(200 \mathrm{mg} / \mathrm{kg})$ was given orally for 4 weeks. Matrix extracellular abundance was determined by HE Staining and measured by METAVIR Fibrosis Score. The results of this study were assayed by SPSS 16 .

Results: P. niruri extract was potent to reduce the matrix extracellular in $2 \% \mathrm{NaCl}$-induced rats compared to control group $(\mathrm{p}<0.05)$.

Conclusion: P. niruri extract was potent to decrease the matrix extracellular in the kidney and uterus of the rats.

\section{Introduction}

Non-infectious disease (NIDs) are the greatest killer in the global that leads 36 million mortalities each year$6 \%$ of all mortalities global. Three number one NIDs (malignancy, cardiovascular and diabetes) and 3 actions hazard factors (insufficient nutrition, disproportionate bodily tactics, and usage of tobacco and risky intake of liqueur. ${ }^{1}$ The growth of NIDs predominance inclusive of extended blood pressure, diabetes mellitus and overweight effects with the enhance of persistent renal illness surveillance approximately $8 \%$ steady with year. ${ }^{2}$ In 2005, approximately 1000 million people (14\%) worldwide had elevated blood stress disease. Elevated blood pressure is the number one threat component for cardiovascular, cerebrovascular and renal diseases that related to the fibrosis contamination in some a part of the body, which includes heart, renal organ, liver and cardiovascular.3,4

The raise of the blood pressure particularly is led with the resource of many factors. Epidemiologic statistics display that genetic in the body, activity stress and sphere issue extended blood stress, 5 but exaggerated mineral salt like sodium chloride $(\mathrm{NaCl})$ utilization is the main issue that drives improved blood pressure, cardiovascular disease and renal disease worldwide. ${ }^{6}$ The system of hypertension that drives by method of overstated mineral salt is as yet incomprehensive, anyway might be identified with renal obstacle to discharge sodium chloride in full-size level. ${ }^{7}$ The relationship among misrepresented mineral salt and blood pressure keeps on being inadequate also 
and actually, that is still denied by methods for a couple of social networks. As of late numerous analysts consideration on the examination about the techniques for renal devastation by sodium chloride, thoughtful nerve movement (SNA) raised through baroreflex instrument and collagen accumulation (Blaustein et al., 2012). 3

In view of the past test on animal model, it showed that $8 \% \mathrm{NaCl}$ improves pulse on precipitously hypertensive rodents (SHRs) and normotensive WistarKyoto rodents (NWKYs).8 The incitement methods are imagined by method of the incitement of angiotensin II by methods for $\mathrm{Na}$ in the way of aldosterone $\rightarrow$ endogenous oabain (EO).9 Angiotensin II initiates vasoconstriction and drives adrenal organ to create aldosterone. Hereinafter, aldosterone turns on distal tubulus to reabsorb $\mathrm{Na}$ and H2O.10,11 Besides, angiotensin II invigorates the proselyte of fibroblast to miofibroblast through pathway of changing development factor-beta1 (TGF- $\beta 1)$. Miofibroblast blends extracelluer framework (ECM), thus, ECM accumulates inside the tubule interstitial territory. 12

Phyllanthus niruri (local name : meniran) extract is utilized in treating kidney and uterus disease. It contain quercitine that be able to increase the expression of PPAR- $\gamma$. The activation drives PPAR- $\gamma$ shapes heterodimer with retinoid $X$ receptors (RXRs) so as co-repressor is synthesized that may block TGF- $\beta 1$ expression. 13

Based on the description above, Phyllanthus niruri extract treatment to the $2 \%$ sodium chloride-induced rats is most likely expected to be anti-fibrotic by describing matrix extracellular that stained by $\mathrm{HE}$ staining in the kidney and uterus organ. $2 \% \mathrm{NaCl}$ is able to induce the fibrotic organ on the rats. 14

\section{Methods}

The research design was experimental study, posttest only with control group design. The study had been affirmed by ethical clearance number 41/EC/FK06/UNIZAR/X/2020, Faculty of Medicine, Al-Azhar
Islamic University, Mataram, NTB.

\section{Preparation Extract of Phyllanthus niruri}

P. niruri plants were harvested from Alung village, Mekar Damai dorp, Praya districts, Central Lombok regency, West Nusa Tenggara province, Indonesia. Furthermore. It was determined by the study center of herb science, Faculty of Health Science, University of Nahdlatul Wathan Mataram. P. niruri plants were extracted by maceration methods in $70 \%$ ethanol.

\section{Procedure of Experimental}

Wistar rats (3 months old) received normal (CTRL; $\mathrm{n}=8)$ or high salt intake $(2 \% \mathrm{NaCl}$ in drinking water) for 4 weeks $(n=16)$. Rats from the group on a high salt intake were administered vehicle (SALT; $\mathrm{n}=7$ ) or Phyllanthus extract (PE) (200 mg/kg) (SALT-PE; $\mathrm{n}=$ 8) during the last week of high salt diet. 14,15. Matrix extracellular abundance was determined by $\mathrm{HE}$ Staining and measured by METAVIR Fibrosis Score. The results of this study were assayed by SPSS 16 .

\section{Analysis of Data}

The result of this study were tested by SPSS 16 . Data was examined for bivariate. Bivariate test was Kruskal-Wallis test $(\mathrm{p}<0.05)$.

\section{Result}

\section{HE Staining of Kidney}

Figure 1 and 2 showed the differences of matrix extracellular in treatment group vs the control group. It means that Phyllanthus extract was able to reduce the abundance of matrix extracellular in the kidney and uterus in sodium chloride -induced fibrotic rats.

Table 1 and 2 showed the METAVIR fibrosis score of kidney and uterus in the treatment group vs the control group. Bivariate test was Kruskal-Wallis test showed the $\mathrm{p}$ value $<0.05$. It means there were the significant differences between treatment vs control group. Therefore, Phyllanthus extract was more potent to reduce the matrix extracellular in sodium chloride induced fibrotic rats. 


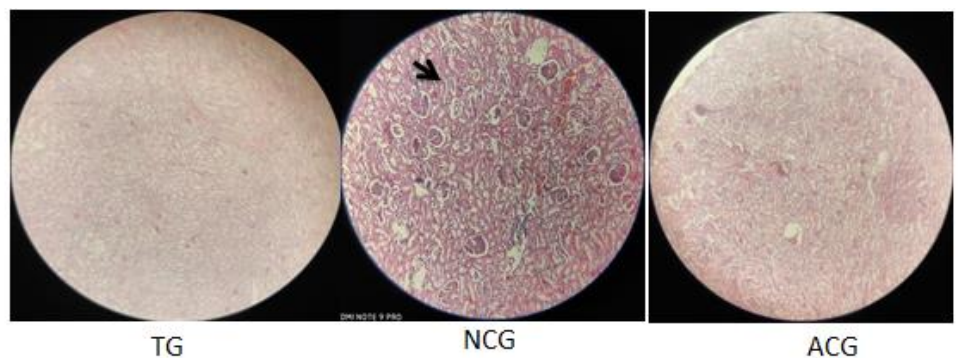

TG (treatment group) $=$ induced by $2 \% \mathrm{NaCl}+200 \mathrm{mg} / \mathrm{Kg}$ P.niruri extract; NCG ( $\mathrm{NaCl}$-control group) $=$ induced by $2 \% \mathrm{NaCl}$ without treatment; $\mathrm{ACG}$ (aquadest-control group) $=$ no induction and treatment. $\rightarrow=$ matrix extracelluler.

Figure 1. HE staining of kidney

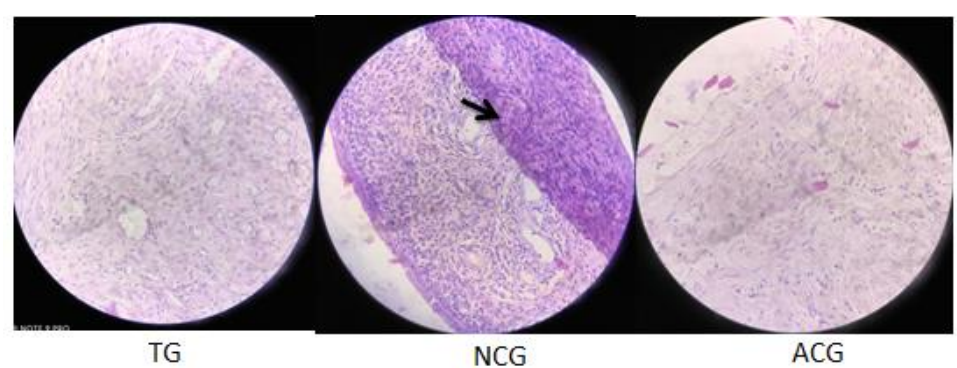

TG (treatment group) = induced by $2 \% \mathrm{NaCl}+200 \mathrm{mg} / \mathrm{Kg}$ P. niruri extract; NCG ( $\mathrm{NaCl}$-control group) $=$ induced by $2 \% \mathrm{NaCl}$ without treatment; $\mathrm{ACG}$ (aquadest-control group) $=$ no induction and treatment. $\rightarrow=$ matrix extracelluler.

Figure 2. HE staining of uterus

Table 1. METAVIR Uterus Fibrosis Score of treatment group

\begin{tabular}{|c|c|c|}
\hline Group & Fibrosis score Mean & P value \\
\hline Treatment group (TG) & $0.4 \pm 0.16$ & 0.001 \\
\hline NaCl-control group (NCG) & $3.9 \pm 0.18$ \\
\hline Aquadest-control group (ACG) & $0.7 \pm 0.52$ & \\
\hline
\end{tabular}

$\mathrm{TG}=$ induced by $2 \% \mathrm{NaCl}+200 \mathrm{mg} / \mathrm{Kg}$ P.niruri extract $\mathrm{NCG}=$ induced by $2 \%$

$\mathrm{NaCl}$ without treatment; $\mathrm{ACG}=$ no induction and treatment

Table 2. METAVIR Oviduct Fibrosis Score of treatment group

\begin{tabular}{|c|c|c|}
\hline Group & Fibrosis score Mean & P value \\
\hline Treatment group (TG) & $1 \pm 0.00$ & 0.04 \\
\hline NaCl-control group (NCG) & $3.9 \pm 0.2$ & \\
\hline Aquadest-control group (ACG) & $1.5 \pm 0.7$ & \\
\hline
\end{tabular}




\section{Discussion}

Based on figure $1 \& 2$ and table $1 \& 2$ in this research showed the difference of treatment and control group significantly $(\mathrm{p}<0.05)$. They indicated that $P$. niruri was potent to decrease the abundance of matrix extracelluler in the kidney and uterus which caused the fibrosis. $2 \% \mathrm{NaCl}$ intake was accompanied by a 2.5 -fold increase in aortic collagen abundance and by a reduction of sensitivity of aortic explants to the vasorelaxant effect of SNP following endothelin-1induced constriction. ${ }^{14}$

Effects of aqueous extract of P. niruri on kidney, liver, and testes of $\mathrm{CCl} 4$ caused hepatotoxic rats have been studied previously. High degrees of malondialdehyde (MDA) have been determined withinside the $\mathrm{CCl} 4$ check organization with good sized discount of MDA degrees in all corporations on P. niruri extract administration. Highest degrees of glutathione (GSH) have been located in P. niruri organization. Activities of alanine transaminase, aspartate transaminase and alkaline phosphatase enzymes have been appreciably decreased withinside the healing organization (P. niruri remedy after $\mathrm{CCl} 4$ injection). Histopathology of liver confirmed lesser diploma of irritation in all P. niruri handled corporations at the same time as the renal and seminiferous tubules confirmed eosinophilic protein casts with symptoms and symptoms of tubular harm and degeneration. Testes additionally confirmed reduced quantity of mature spermatozoa. The consequences recommend that P. niruri has anti-oxidant and hepato-protecting hobby with related deleterious outcomes on kidney and testes. 16

Phyllanthus niruri extract allows to hold close to kidney feature and stops histopathological adjustments through ameliorating oxidative stress, inflammation, fibrosis and apoptosis at the same time as improving proliferation of the kidney in diabetes mellitus. 17 Administration of Phyllanthus sp extract substantially reduced the ranges of collagen and tissue inhibitors of matrix metalloproteinases (TIMPs); and definitely modulated the expression of matrix metalloproteinases (MMPs). 18

\section{Conclusion}

P. niruri extract was potent to decrease the matrix extracellular in the kidney and uterus of the rats.

\section{Acknowledgments}

We thank you to DIKTI of Republic Indonesia for the funding research number B/87/E3/RA.00/2020.

\section{References}

1. WHO., 2010, Global status report on noncommunicable maladys, Geneva, Switzerland.

2. Baltatzi, M.C.H. S., Hatzitolios A., 2011, Role of angiotensin converting enzyme inhibitors and angiotensin receptor blockers in elevated blood pressure of chronic renal organ malady and renoprotection. Hippokratia 15: 2732.

3. Blaustein, M.P., et al., 2012, How $\mathrm{NaCl}$ raises blood pressure: A new paradigm for the pathogenesis of saltdependent elevated blood pressure. Am J Physiol Heart Circ Physiol 302: H1031-H1049.

4. Cox, N., Pilling, D., Gomer, R.H., 2012, NaCl potentiates human fibrocyte differentiation. PLoS One 7: 1-9.

5. Beevers, G., Lip, G.Y.H,, O’Brien, E., 2001, $\mathrm{ABC}$ of elevated blood pressure: "The pathophysiology of elevated blood pressure". BMJ 322: 912-916.

6. He, F.J., Jenner, K.H., MacGregor, G.A., Avenue, G., 2012, Telmisartan exerts renoprotective actions via peroxisome. Elevated blood pressure 59: 308-316.

7. Meneton, P., et al., 2005, Links between dietary salt intake, renal salt handling, blood pressure and cardiovascular maladys. Physiol Rev 86: 679-715.

8. Yu, H.C.M, Burrell, L.M., Black, M.J., Wu, L.L., Dilley, R.J., 1998, Salt induces myocardial and renal fibrosis in normotensive and hypertensive rats. Circulation 98: 2621-2628. 
9. Leenen, F.H.H., 2010, The central role of the brain aldosterone - "ouabain" pathway in saltsensitive elevated blood pressure. BBA Mol Basis Dis 1802: 1132-1139.

10. Jöhren, O., Dendorfer, A., Dominiak, P., 2004, Cardiovascular and renal function of angiotensin II type-2 receptors. Cardiovasc Res 62: 460-467.

11. Starr, C., McMillan, B., 2012, Human Biology. 9th Edn, Brooks/Cole Cengage Learning, Canada.

12. Mezzano, S.A., Ruiz-Ortega, M., Egido, J., 2001, Angiotensin II and renal fibrosis. Elevated blood pressure 38: 635638.

13. Rotman, N., Wahli, W., 2010, PPAR modulation of kinase-linked receptor signaling in physiology and malady. Physiology 25: 176185.

14. Grigorova, Y.N., Juhasz, O., Zernetkina, V., Fishbein, K.W., Lakatta, E.G., Fedorova, O.V., and Bagrov, A.Y., 2016. Aortic Fibrosis, Induced by High Salt Intake in the Absence of Hypertensive Response, Is Reduced by a Monoclonal Antibody to Marinobufagenin. American J. of Hypert. 29(5) : 641-646.

15. Amin, A.Z. et al., 2013. Gene expression profiling reveals underlying molecular mechanism of hepatoprotective effect of Phyllanthus niruri on thioacetamide-induced hepatotoxicity in Sprague Dawley rats. BMC Complementary and Alternative Medicine 2013, 13:160.

16. Manjrekar, A. P., Jisha, V., Bag, P. P., Adhikary, B., Pai, M. M ., Hegde, A ., \& Nandini, M., 2008. Effect of Phyllanthus niruri Linn. treatment on liver, kidney and testes in $\mathrm{CCl} 4$ induced hepatotoxic rats. Indian J. Exp. Bio. 46: 514-520.

17. Giribabu, N., Karim, K., Kumar, E., Kilari, Salleh, N. 2017. Phyllanthus niruri leaves aqueous extract improves kidney functions, ameliorates kidney oxidative stress, inflammation, fibrosis and apoptosis and enhances kidney cell proliferation in adult male rats with diabetes mellitus. J Ethnopharmacol. 205:123-137.

18. Narayanan, B.S., Latha, P., \& Rukkumani, R., 2010. Protective effects of Phyllanthus amarus on fibrotic markers during alcohol and polyunsaturated fatty acid-induced toxicity. Toxicol Mech Methods. 21(1):48-52. 